\title{
$\mathrm{HCl}$ and Menopause: Designing With and Around the Aging Body
}

\section{Agatha Tutia}

University of Washington

Human-Computer Interaction + Design

Seattle, WA, USA

atutia@uw.edu

\section{Lan $\mathrm{Vu}$}

University of Washington

Human-Computer Interaction + Design

Seattle, WA, USA

Itvu@uw.edu

\author{
Kelda Baljon \\ University of Washington \\ Human-Computer Interaction + Design \\ Seattle, WA, USA \\ kbaljon@uw.edu
}

\section{Daniela K. Rosner}

University of Washington

Human-Centered Design and Engineering

Seattle, WA, USA

dkrosner@uw.edu

\section{ABSTRACT}

With growing concern for the intimate dimensions of technology development, $\mathrm{HCl}$ scholars have begun to grapple with who wields power in design around the body. However, beyond menstruation, few studies have sought to examine the role of technology design in the later stages of life for menstruating people. This paper considers menopause as a central, but overlooked life phase informing the design of future intimate technologies. We review empirical analysis of menopausal experiences and design provocations that emerged from our work. We end with a reflection on the opportunities and pitfalls around menopause design.

Permission to make digital or hard copies of part or all of this work for personal or classroom use is granted without fee provided that copies are not made or distributed for profit or commercial advantage and that copies bear this notice and the full citation on the first page. Copyrights for third-party components of this work must be honored. For all other uses, contact the owner/author(s).

CHI'19 Extended Abstracts, May 4-9, 2019, Glasgow, Scotland UK

(c) 2019 Copyright held by the owner/author(s).

ACM ISBN 978-1-4503-5971-9/19/05.

https://doi.org/10.1145/3290607.3299066 
${ }^{1}$ Menopause is not a disease, but a natural transition of life. Instead of using the word "symptom," we use "biological change" or "signal" to define the effects of menopause. Signals can include hot flashes, night sweats, vaginal dryness, and sleeping difficulties.

\section{CCS CONCEPTS}

- Human-centered computing $\rightarrow$ Empirical studies in $\mathrm{HCl}$;

\section{KEYWORDS}

Menopause; Care; Intimate technology

\section{ACM Reference Format:}

Agatha Tutia, Kelda Baljon, Lan Vu, and Daniela K. Rosner. 2019. HCl and Menopause: Designing With and Around the Aging Body. In CHI Conference on Human Factors in Computing Systems Extended Abstracts (CHI'19 Extended Abstracts), May 4-9, 2019, Glasgow, Scotland UK. ACM, New York, NY, USA, 8 pages. https://doi.org/10. $1145 / 3290607.3299066$

\section{INTRODUCTION}

Over the last few decades, $\mathrm{HCl}$ scholars have embraced a feminist agenda that elevates typically under-recognized bodies and phases of life through technology design $[6,11,20,21]$. Such attention to intimacy counters widespread depictions of the menstruating body as an abject site of objectification that lacks a multi-phase existence [8]. However, new computational tools such as apps that track menstrual cycles threaten to further expose and commodify intimate spaces. In doing so, $\mathrm{HCl}$ scholars warn, designers risk desensitizing the body and mind [23] .

This paper seeks to address this concern by examining computing tools in and around menopause. Building on a small but growing $\mathrm{HCl}$ literature on menopause [14, 15, 19, 25], we sought to investigate this phase of life without applying an intervention. We describe our work in order to examine and extend the possibilities of designing for the menopausal experience through intimate and thoughtful computing.

Menopause, the body's permanent cessation of menstruation, is not merely a biological phenomenon, but an experience impacted by cultural, generational, and social factors [4, 18, 26]. Expectations and attitudes vary considerably due to prior (or lack of) knowledge [7], and signals ${ }^{1}$ range in frequency and severity throughout the phases [9].

Menopause is a significant part of life for millions of people. In 2017 alone, according to the World Bank, 359.6 million women ages 65 and older underwent menopause [5]. Each day, roughly 6,000 new people experience first signs of menopause [17]. In sum, half the world's population will, is going to, or has gone through menopause which has led to public discussion [2,12] and a voiced desire for support [10]. As technology inevitably entangles itself to this phase of life, we asked ourselves: How can we avoid framing menopause as a problem requiring a single technological response and instead, how can we, the $\mathrm{HCl}$ community, design for the menopausal experience? 


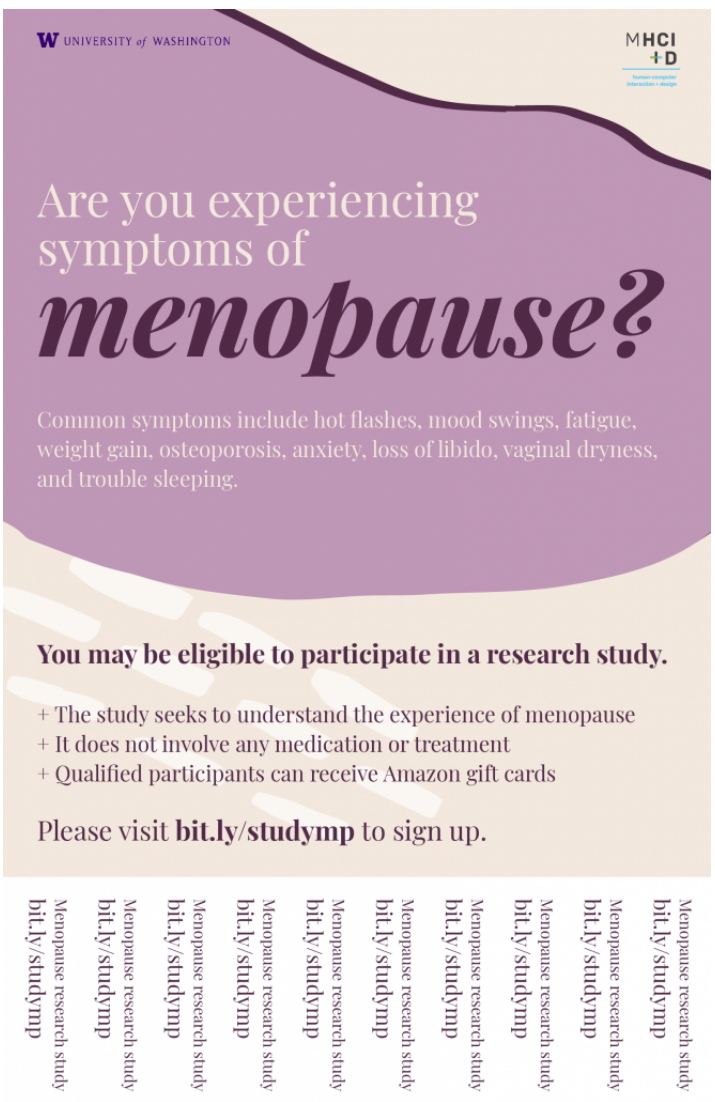

Figure 1: Flier used for participant recruitment

\section{RELATED WORKS}

\section{Intimate Care, the Body + HCI}

$\mathrm{HCl}$ is increasingly becoming more engaged with the everyday and intimate spaces [6]. Among menstruating bodies in particular, intimate care has been historically marked by taboo in ways that limit the potential of research to inform and support access to quality care [1]. Almeida et al. enacted a call to action in 2016 to the $\mathrm{HCl}$ community to forgo embarrassment and apprehension of the "sexual parts," and to encourage additional design for intimate spaces [1]. Since then, research answering that call has included menstruation [11, 21], reproduction and sexual health [16, 22], and menopause. However, there is still resistance for researchers to design "for the intersection between technology and the female body" due to associated stigma to the topic [3], and the moral and political agendas influencing research decisions [8].

Recent $\mathrm{HCl}$ scholarship has voiced a concern for the commodification of intimate activities through smart devices and apps, highlighting the risk of losing bodily sensations and empathy due to hyperconnectivity [23]. In designing for the body, researchers must respect the body and question the effects of a technological solution surrounding intimate experiences [13, 22]. As more researchers engage with the relationships of intimate care, the body, and technology; we aim to further aid researchers in intimately designing for the menopausal body through our research insights and design provocations.

\section{Menopause $+\mathrm{HCl}$}

As of writing, there is an increasing, yet acutely modest attention to menopause within $\mathrm{HCl}$. One area of research focuses on personalized mobile health application interventions [15, 24, 25], another trend looks at specific contexts like colour perception [14] and hormone contraception [19].

Although promising, this limited engagement with menopause in $\mathrm{HCl}$ evidences the field's wider disinterest in the aging body, particularly the aging bodies of women and other menstruating people. This disinterest suggests discriminatory practices that need addressing. In response, we contribute an examination of the menopause experience and what it means to elevate the aging body in and through $\mathrm{HCl}$.

\section{METHODS: CONNECTING WITH THE MENOPAUSAL EXPERIENCE}

We recruited our participants by posting flyers in various socioeconomically ranging neighborhoods in Seattle, using advertisements on Craigslist and Reddit, reaching out to various groups on Facebook and Meetup, and through word-of-mouth. We identified our groups on social media through indicators like "menopause," "women's group," "midlife group," and "moms." Through our flyers and online presence, we included a link to our research study's website and screener survey. By using flyers in different neighborhoods, we aimed to gain a diverse and intersectional sample of participants. Our 


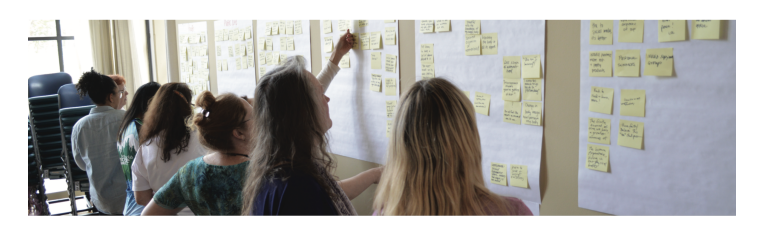

Figure 2: Participatory workshop

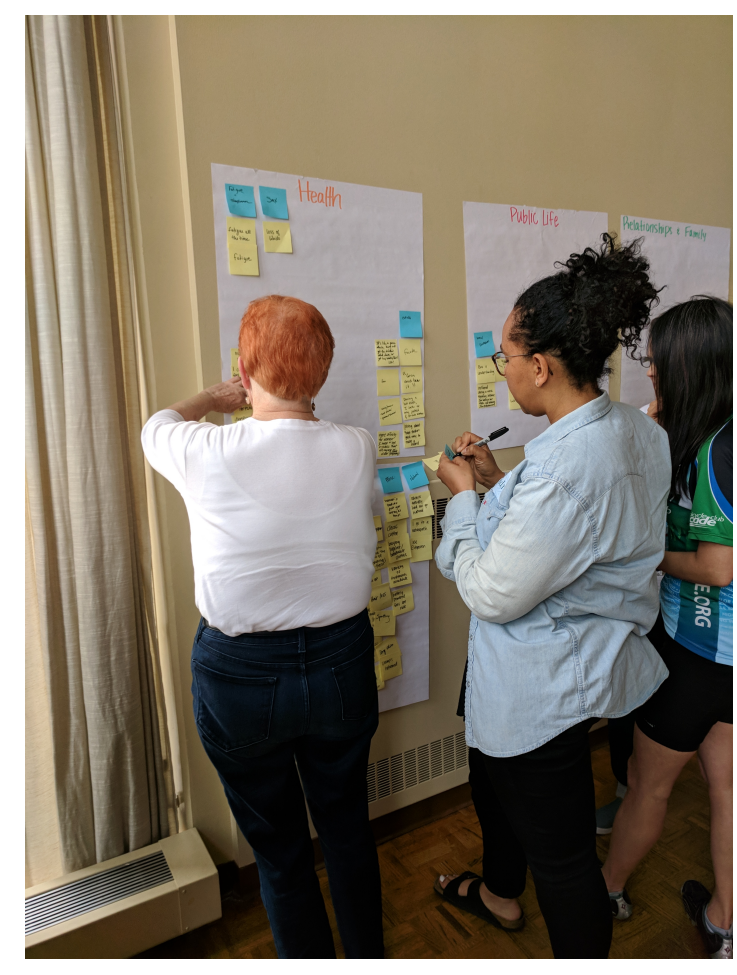

Figure 3: Participants writing and sharing aspects of their menopausal experience sample involved 17 cisgender women including 7 mothers, 6 non-caucasians, 2 women who underwent hysterectomies (the surgical removal of the uterus). We had one transgender man who completed our survey, but after several attempts, we were unable to connect with the individual.

We conducted six semi-structured interviews, a two and a half hour workshop, and three final semi-structured interviews. The interviews and workshop were audio recorded, transcribed and thematically coded.

We coordinated a workshop because it allowed us to engage with a collective mindset and receive personal testimonies about their biological changes. The workshop began with each participant writing a letter to her pre-menopausal self, followed by a focus group discussion of these letters and the challenges the participants have experienced during menopause. In the second half of the workshop, the participants wrote observations about menopause on post-it notes, worked in pairs to organize the post-it notes into groupings, and then each chose a post-it note they would like to see changed for themselves and a post-it note they would like to see changed for the greater community.

Prior to the workshop, we primed the walls with six posters: Health, Knowledge, Public Life, Relationships/Family, Self Image, and Other. Within each theme, we posted quotes from the first round of semi-structured interviews to allow participants to become comfortable with the concept of ideation. Quotes were reviewed to ascertain limited influence in the participants' participation.

Three of the authors were each assigned participants to code and reviewed another author's set of codes. Initial codes were generated prior to the workshop through informal affinity diagramming means, codes were continually reorganized and refined thereafter. We reviewed the most frequently used codes as a starting point and then continued analysing outlying, but otherwise impactful data. After analysis, the three authors discussed emerging themes and insights.

\section{FINDINGS AND DISCUSSION: LEARNING FROM MENOPAUSE}

In the sections that follow, we describe four major insights that emerged from our examinations of the menopausal experience. These insights are particular to our study while also acting as directives for future scholarship and design beyond the particular people with whom we spoke. We end by describing five design provocations informed by these insights and developed to stimulate further discussion of the menopausal experience in $\mathrm{HCl}$.

\section{Research Insights}

Insight 1: Because menopause is a stigmatized topic, our participants encountered a culture of silence that limited their exposure to menopausal experience and made them feel emotionally and practically under-prepared. "It's just like what women do. We suffer in silence," shared Clotilde. Menopause was viewed not as a life-threatening condition, but rather a quality of life issue expected to be silently endured. Many of our participants noted a low-level interest in creating a broader discussion about 
Daughter, Now Mother Consider the experience of Lucy, a Vietnamese immigrant now living in the Pacific Northwest. During an interview, she recounted a family response to her mother's adverse reactions to hormone replacement therapy (HRT). "She was bleeding out of the blue after not having a period. She thought she was dying and went to the ER. My sister and I started bawling on the phone that mom is dying... And that was it. Never discussed again. [Mom] went home. That's it. 'I'm fine."'

Now the mother of a young woman, Lucy discussed how important it was for her and her teenage daughter to take classes about their bodies and its intimate aspects so that her daughter would be better prepared for her own body's changes including menopause.
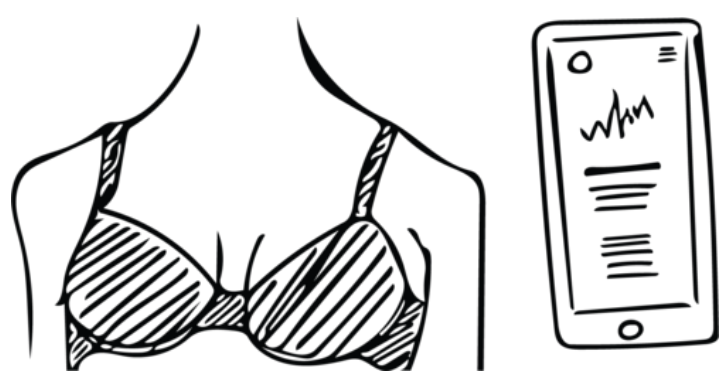

Figure 4: A design provocation depicting a smart bra that cools down the skin once triggered the topic. Maya pointed out on a generational shortcoming, "Yeah, it's interesting because the baby boomers who tend to drive a lot of social thought... they're way past this and they didn't make this one one of their priorities."

This pervasive silence had widespread repercussions for the livelihoods of the people whom we spoke with. Six participants noted a lack or mismatch of expectations while nine participants expressed wanting to have learned more about menopause earlier. Because of this disconnect between menopausal expectations and realities, participants described feeling confused, frustrated, and/or isolated. "I wish someone (a doctor or any educated person) would have told me what I would, or could, experience later in the menopause state," one woman explained. For several participants, the endurance of silence unfolded across generations. Ten participants described maternal figures who refused to discuss the topic of menopause. In a response to this lack of communication, five participants described being more vocal about preparing their own daughters through open conversation. Communication rituals around menopause passed from from parent to child both perpetuate and intervene within longstanding silence and under-preparedness.

In short, participants described the benefits of breaking the silence around menopause and allowing people to unashamedly share their experiences with others. Such experiences of sharing information often led to relief through acknowledgement, a sense of legitimacy, and information exchange. By reframing menopause as integral to human experience, designers might position aging life as an opportunity for emotional growth and increased agency.

Insight 2: Participants described experiencing a fluctuating loss of control over their bodies. Participants spoke of experiencing an emotional disconnection with their bodies, a feeling that ranged in intensity. During moments when they were not aware of the signals associated with the transition into menopause, multiple people described feeling as if they were "going crazy." For Roberta, the transition was not adverse, but there was a period of time in which she questioned whether her signals were "normal" or not. Others described understanding their overall experiences as a part of life, but then juxtaposed their acceptance with ephemeral annoyance. For example, one participant who described feeling positively about menopause also noted that her hot flashes could be "really really really extreme" and discussed being highly cognizant of her body odor. During the workshop, another participant, Ramona, echoed these tensions as she read aloud from her letter to her pre-menopausal self about honoring the body: "I grew up at a time or area where the sacred aspect of this part of being a woman was not acknowledged or paid honor to. At a later age in my life, I became more spiritual and stepped onto a path of paying more attention to and honoring the body through knowledge." Such recollections point the the underlying sense of unease around embracing menopause as an important life phase while encountering disruptions that amplified emotional distress. 

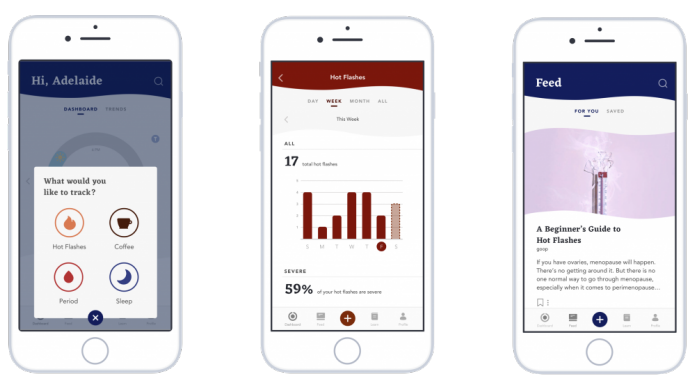

Figure 5: A design provocation app for selftracking and educational opportunities

Smart Cool Down Bra utilizing the form of a bra, an intimate and iconic garment, and adapting it to track heart rate, skin conductivity, and hot flashes; it can preemptively warn and cool the wearer during a hot flash. How can such technology and textiles intervene with other menopausal signals like vaginal dryness or night sweats? How might it also prompt unwanted additional stress or anxiety?

Interactive Stories Map curating a collection of people's stories within an interactive and multicultural map experience. It disrupts isolation across boundaries. How might such technology break the silence and normalize menopausal experience? How might the same tool get co-opted by non-menopausal users or by corporations for profit gains?

Adaptive Gatherings Through an adaptive gathering tool, menopausal people seeking support can benefit through a group meeting with set details and purpose based off the party's accumulated preferences. How can designers use such to technology encourage human-human interactions? What if technology only played a minimal, but impactful role in the menopausal experience? How might such technology fail to bring benefits? What existing resources might it displace, disrupt, or curtail?
Insight 3: Participants found the effects of non-induced menopause as deeply intertwined with wider attitudes and understandings around aging. With aging comes menopause, and with menopause often comes an aged life. When Roberta was asked about how menopause impacted her self image, she responded that it did not really affect her, but that "a lot of women go, 'Oh my god, [this] means I'm old now.' When menopause is not induced, participants described the body's biological changes around both aging and menopause as occurring concurrently and sometime interchangeably. They often attributed changes in forgetfulness and weight (changes that are commonly attributed to aging generally) as a result of their menopause, in particular.

However, menstruation did not always coincide with aging. One participant, a cancer survivor, underwent menopause twice due to chemotherapy at a young age. While undergoing menopause, other participants described feeling the weight of society's discrimination toward aging women. One participant explained that "you become invisible." These insights suggest attending to and engaging with the menopausal body as an aging body.

Insight 4: Participants' responses to the end of menstruation consisted of a range of emotions from relief to regret. When transitioning into menopause, participants described new emotional and biological experiences. The cessation of menstruation involved developing cramps of varying severity, needing new menstruation products at often high costs, and feeling a renewed desire to become a parent or have additional children.

Ten participants described feeling relieved that their periods would soon be over. As one participant explained, "We suffered through menstruation and menstruation, for me, was far worse. I'm glad to be done with that!" Others did not want children and looked forward to no longer being cautious about becoming pregnant. Dara explained "I love children. I just don't want my own and [getting pregnant] would have been a horrible thing to be faced with."

However, other participants felt deep regret. The participant who underwent induced menopause due to cancer treatment followed up her treatment with a hysterectomy and oophorectomy (the surgical removal of the ovaries). Before the procedures she had hoped to have children. In an interview, she recalled the surgery as "one of the most difficult decisions [she] ever had to make during this entire journey": choosing to live over the ability to create life. Broadly, participants described feeling a broad range of emotions during the onset of menopause.

\section{Design Provocations}

Based upon the above insights, we present brief design provocations on the left sidebar. We believe these provocations act as multiple technological concepts addressing various, but limited aspects of the menopausal experience. It is our hope to spark conversation on the possible opportunities and consequences of designing computational systems around menopause. 


\section{CONCLUSION}

In this paper, we offered a rare glimpse at designing with and around menopause within $\mathrm{HCl}$, a perspective that is becoming particularly important as the field increasingly attends to intimacy. We sought to avoid framing menopause as a problem requiring a single technological response and instead, explored how the $\mathrm{HCl}$ community could design for the menopausal experience. In our elaboration on the cross-sections of intimate care, the body, and interaction design, we have identified multiple areas for future scholarship and attention. Our findings point to the need for additional research with transgender populations, global perspectives, and induced menopause groups (oophorectomy, radiation, chemotherapy, premature ovarian failure). Taking lessons from our fieldwork, we suggest that future $\mathrm{HCl}$ research foreground the menopausal body as a pivotal site of learning and engagement.

\section{ACKNOWLEDGMENTS}

We thank our participants for kindly sharing their experiences; along with Uba Backonja, Nancy Woods, Michael Smith, Chris Hannon, Paola Reyes, Brian Greene, and Elizabeth Sanocki. Research for this paper was partially supported by funding from NSF Grants 1453329, 1423074, and 1523579.

\section{REFERENCES}

[1] Teresa Almeida, Rob Comber, and Madeline Balaam. 2016. HCl and Intimate Care As an Agenda for Change in Women's Health. In Proceedings of the 2016 CHI Conference on Human Factors in Computing Systems (CHI '16). ACM, New York, NY, USA, 2599-2611. https://doi.org/10.1145/2858036.2858187

[2] Good Morning America. 2018. Your most common menopause questions answered. Retrieved October 13, 2018 from https://www.youtube.com/watch?v=GID26xz1-aE

[3] Madeline Balaam and Lone Koefoed Hansen. 2017. Women’s Health @ CHI. Interactions 25, 1 (Dec. 2017), 6-7. https: //doi.org/10.1145/3169797

[4] Karen D. Ballard, Diana J. Kuh, and Michael E.J. Wadsworth. 2001. The role of the menopause in women's experiences of the 'change of life'. Sociology of Health and Illness 23, 4 (Jul. 2001), 397-424. https://doi.org/10.1111/1467-9566.00258

[5] The World Bank. 2018. Population ages 65 and above, female (percentage of total). Retrieved October 13, 2018 from https://data.worldbank.org/indicator/SP.POP.65UP.FE.ZS

[6] Shaowen Bardzell and Jeffrey Bardzell. 2011. Towards a Feminist HCI Methodology: Social Science, Feminism, and $\mathrm{HCl}$. In Proceedings of the SIGCHI Conference on Human Factors in Computing Systems (CHI '11). ACM, New York, NY, USA, 675-684. https://doi.org/10.1145/1978942.1979041

[7] Carina Berterö. 2003. What do women think about menopause? A qualitative study of women's expectations, apprehensions and knowledge about the climacteric period. International Nursing Review 50, 2 (Jun. 2003), 109-118. https://doi.org/10. 1046/j.1466-7657.2003.00185.x

[8] Sheelagh Carpendale, Shaowen Bardzell, Margaret Burnett, Neha Kumar, and Madeline Balaam. 2018. Panel: Extending Conversations About Gender and HCl. In Extended Abstracts of the 2018 CHI Conference on Human Factors in Computing Systems (CHI EA '18). ACM, New York, NY, USA, Article panel03, 6 pages. https://doi.org/10.1145/3170427.3186325

[9] Boston Women's Health Book Collective and Judy Norsigian. 2006. Our Bodies, Ourselves: Menopause (1st. ed.). Touchstone, New York, NY, USA 
[10] Facebook. 2018. Menopause Support Group. https:/www.facebook.com/groups/439232282854798

[11] Sarah Fox. 2018. Design, Maintenance, and the Menstruating Body. In Proceedings of the 2018 ACM Conference Companion Publication on Designing Interactive Systems (DIS '18 Companion). ACM, New York, NY, USA, 375-378. https://doi.org/10. 1145/3197391.3205386

[12] Isabel Gillies. 2018. An Author on Going Through Menopause at 37. Retrieved October 13, 2018 from https://goop.com/ work/relationships/a-writer-on-early-unexpected-menopause/

[13] Sarah Homewood. 2018. Designing for the Changing Body: A Feminist Exploration of Self-Tracking Technologies. In Extended Abstracts of the 2018 CHI Conference on Human Factors in Computing Systems (CHI EA '18). ACM, New York, NY, USA, Article DC11, 4 pages. https://doi.org/10.1145/3170427.3173031

[14] Mayuko Iriguchi, Hiroki Koda, and Nobuo Masataka. 2018. Colour Perception Characteristics of Women in Menopause. In Proceedings of the 2018 International Joint Workshop on Multimedia Artworks Analysis and Attractiveness Computing in Multimedia (MMArt\&\#38;ACM’18). ACM, New York, NY, USA, 20-25. https://doi.org/10.1145/3209693.3209694

[15] Mirim Lee, Bon-chang Koo, Hee-seok Jeong, Joongsin Park, Juhee Cho, and Jun-dong Cho. 2015. Understanding Women's Needs in Menopause for Development of mHealth. In Proceedings of the 2015 Workshop on Pervasive Wireless Healthcare (MobileHealth '15). ACM, New York, NY, USA, 51-56. https://doi.org/10.1145/2757290.2757295

[16] Kerry McKellar, Elizabeth Sillence, and Michael A. Smith. 2017. Exploring the Preferences of Female Teenagers when Seeking Sexual Health Information Using Websites and Apps. In Proceedings of the 2017 International Conference on Digital Health (DH '17). ACM, New York, NY, USA, 43-47. https://doi.org/10.1145/3079452.3079497

[17] The American Congress of Obstetricians and Gynecologists. 2011. 2011 Women's Health Stats \& Facts. https://www. acog.org/-/media/newsroom/mediakit.pdf

[18] J. Pitkin. 2010. Cultural issues and the menopause. Menopause International 16, 4 (Dec. 2010), 156-161. https://doi.org/10. 1258/mi.2010.010032

[19] Raodah, Masni, and Ridwan M. Thaha. 2018. Relationship Between Hormonal Contraception Use with Age of Menopause Among Elderly at Posyandu Sidodadi Village Wonomulyo Subdistrict Polewali Mandar District. In Proceedings of the International Conference on Healthcare Service Management 2018 (ICHSM '18). ACM, New York, NY, USA, 68-72. https: //doi.org/10.1145/3242789.3242801

[20] Daniela K. Rosner. 2018. Critical Fabulations. John Wiley \& Sons, Inc., New York, NY, USA.

21] Marie Louise Juul Søndergaard and Lone Koefoed Hansen. 2016. PeriodShare: A Bloody Design Fiction. In Proceedings of the 9th Nordic Conference on Human-Computer Interaction (NordiCHI '16). ACM, New York, NY, USA, Article 113, 6 pages. https://doi.org/10.1145/2971485.2996748

[22] Marie Louise Juul Søndergaard and Lone Koefoed Hansen. 2018. Intimate Futures: Staying with the Trouble of Digital Personal Assistants Through Design Fiction. In Proceedings of the 2018 Designing Interactive Systems Conference (DIS '18). ACM, New York, NY, USA, 869-880. https://doi.org/10.1145/3196709.3196766

[23] Marie Louise Juul Søndergaard and Kasper Hedegård Schiølin. 2017. Bataille’s Bicycle: Execution and/as Eroticism. Open Humanities Press, London, Great Britain, UK, 179-197.

[24] Amaury Trujillo and Maria Claudia Buzzi. 2016. Participatory User Requirements Elicitation for Personal Menopause App. In Proceedings of the 9th Nordic Conference on Human-Computer Interaction (NordiCHI '16). ACM, New York, NY, USA, Article 102, 6 pages. https://doi.org/10.1145/2971485.2996737

[25] Amaury Trujillo and Maria Claudia Buzzi. 2018. Towards a Fuzzy Rule-based Systems Approach for Adaptive Interventions in Menopause Self-care. In Adjunct Publication of the 26th Conference on User Modeling, Adaptation and Personalization (UMAP '18). ACM, New York, NY, USA, 53-56. https://doi.org/10.1145/3213586.3226193

[26] Rebecca L. Utz. 2011. Like mother, (not) like daughter: The social construction of menopause and aging. Journal of Aging Studies 25, 2 (Apr. 2011), 143-154. https://doi.org/10.1016/j.jaging.2010.08.019 